\title{
New data on internal waves on the sea shelf based on combined monitoring with a panoramic camera and ADCP
}

\author{
A.N. Serebryany ${ }^{1,3}$, O. G. Konstantinov ${ }^{2}$ \\ ${ }^{1}$ Shirshov Institute of Oceanology RAS, Moscow, 117997, Russia \\ ${ }^{3}$ Il'ichev Pacific Oceanological Institute RAS, Vladivostok, 690041, Russia \\ ${ }^{2}$ Andreyev Acoustics Institute, Moscow, 117036, Russia \\ E-mail: serebryany@hotmail.com
}

\begin{abstract}
Observations of internal waves in the shelf zone, based on combined monitoring of the surface and thickness of the sea, are discussed. The measurements were carried out in the coastal zone of the Sea of Japan in the Gulf of Peter the Great. The experiment included scanning the sea surface from the shore by panoramic camera while approaching the coastal region of internal wave trains. At the same time, measurements were carried out in the sea by ADCP from an anchored yacht. As a result, new data on the features of internal waves on the shelf of the tidal sea were obtained. A more frequent than half-day periodicity of the appearance of internal solitons in the coastal zone was revealed. Almost synchronous approaches to the coastal zone of individual trains of internal solitons propagating at an angle to each other were recorded, which indicates various mechanisms of their generation. The waves in the trains differ not only in direction but also in length and speed of propagation.
\end{abstract}

Accepted: 15.09 .2020

DOI: 10.21046/2070-7401-2020-17-6-122-126

\section{Introduction}

Internal waves are a widespread hydrodynamic phenomenon in the ocean and its continental margins, which plays an important role in mixing the stratified medium. Internal waves propagate inside the sea, but they also tend to manifest themselves on the sea surface. This is due to the fact that the orbital flows of internal waves create near the surface zones of convergence and divergence, spaced at a wavelength. In the convergence zones there is an intensification of surface waves and, accordingly, an increase in surface roughness. In the divergence zone, on the contrary, a weakening of surface waves occurs up to the formation of smoothed water areas - slicks. These features of the properties of internal waves make it possible to observe them through surface manifestations both with the help of radars and with the naked eye [1]. As an example figure 1 shows a photograph of the sea surface at the entrance to Vityaz Bay in the Sea of Japan during the passage of a packet of internal waves. Internal waves manifest themselves as a group of slick bands. The manifestation of internal waves on the surface helps to obtain important new information about internal waves.

To obtain more detailed information about internal waves on the shelf of the Sea of Japan, we conducted a special experiment in which we combined observations of the surface manifestations of internal waves and direct measurements in the water column. We used the experimental coastal complex for long-term optical observations of the sea surface [2], which was developed by one of the authors of this paper. The measurements were carried out in September 2004 in the Peter the Great Bay of the Sea of Japan, in the water area adjacent to Cape Schulz, which protrudes into the open sea. In this 
region internal waves generated at the continental slope propagate unhindered along the shelf reaching the coastal zone. Moreover, they often manifest themselves on the surface in the form of slicks as shown in the photo (figure 2). The experiment consisted in tracking the sea surface in the coastal zone using a scanning camera mounted on a high steep shore, and simultaneously measuring the currents and parameters of internal waves from a yacht anchored in the camera's field of view.

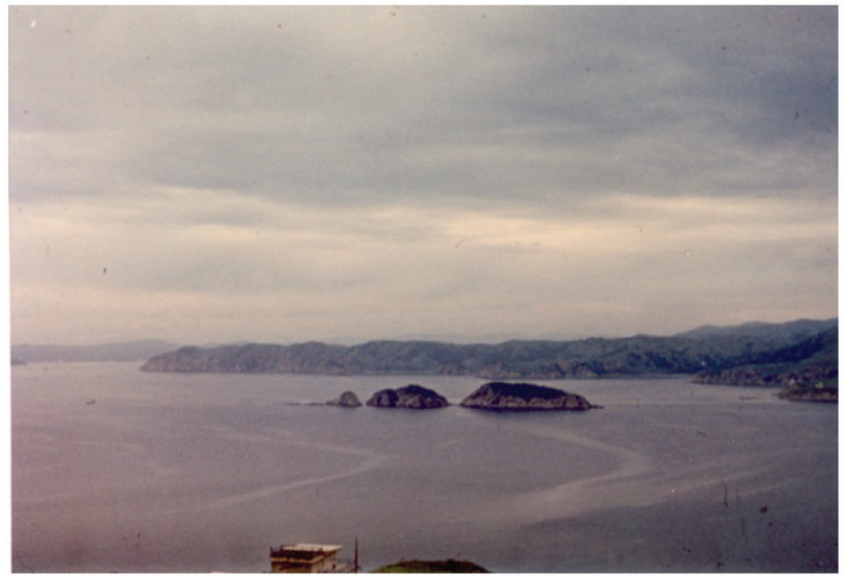

Figure 1. The manifestation of internal waves in the form of slick bands on the surface of the sea. Internal waves enter the Vityaz Bay, Sea of Japan.

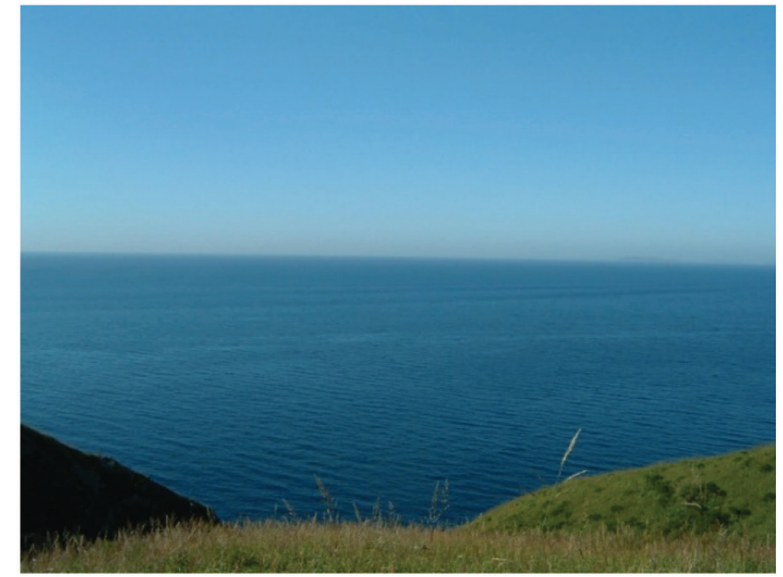

Figure 2. Slick stripes on the sea surface generating by internal waves moving to the shore. View from the shore of Cape Schulz.

\section{Results of measurements}

\subsection{Scanning camera measurements of the sea surface}

During panoramic scanning, a camera mounted on a high shore took sequential pictures in separate areas, which were then stitched together during processing. The result was a wide panoramic shot (figure 3).

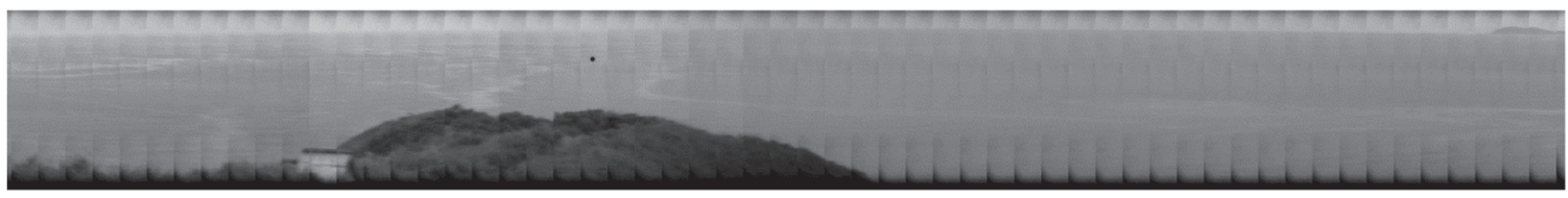

Figure 3. Panorama of the coastal zone on September 20, 2004 (vertical polarized camera). The position of the anchored yacht in the sea is shown by a black dot.

The panoramic camera recorded two spaced-apart trains of internal waves moving toward the shore at different angles. Three consecutive (compressed) images taken on September 20, 2004 at 19:14, 19:34 and 20:10 local time (figure 4) show two groups of dark stripes near the point indicating the location of the yacht. The first group consisted of 3 wider bands, the second of 6 narrower ones. The almost rectilinear fronts of the bands of these two groups were oriented at an angle of 30 degrees to each other. The first group of bands moved directly north in a direction close to the normal of the coastline. The second one turned along with the alongshore current and propagated north-westward to $330^{\circ}$ direction. In 56 minutes both systems of strips noticeably advanced to the coast. In addition to slick stripes, characteristic light stripes located almost normal to the shore, indicating the boundaries of the frontal sections, are clearly visible in the photographs. Note that if in case of radar images of the sea surface, the lighter areas indicate ripple enhancement, and the darker areas correspond to slicks, then the opposite is true in the optical image. Slicks look light, and strips of roughness look dark. The processing of a set of successive photographs of the surface of the sea was carried out, which included the transfer to the "plane" of photographs using the affine conversion. After this procedure, estimates of wave speeds and directions of their propagation were obtained, and estimates of wavelengths were made. It was found that the speed of internal waves in the first group was $17 \mathrm{~cm} / \mathrm{s}$, and in the second $37 \mathrm{~cm} / \mathrm{s}$. 

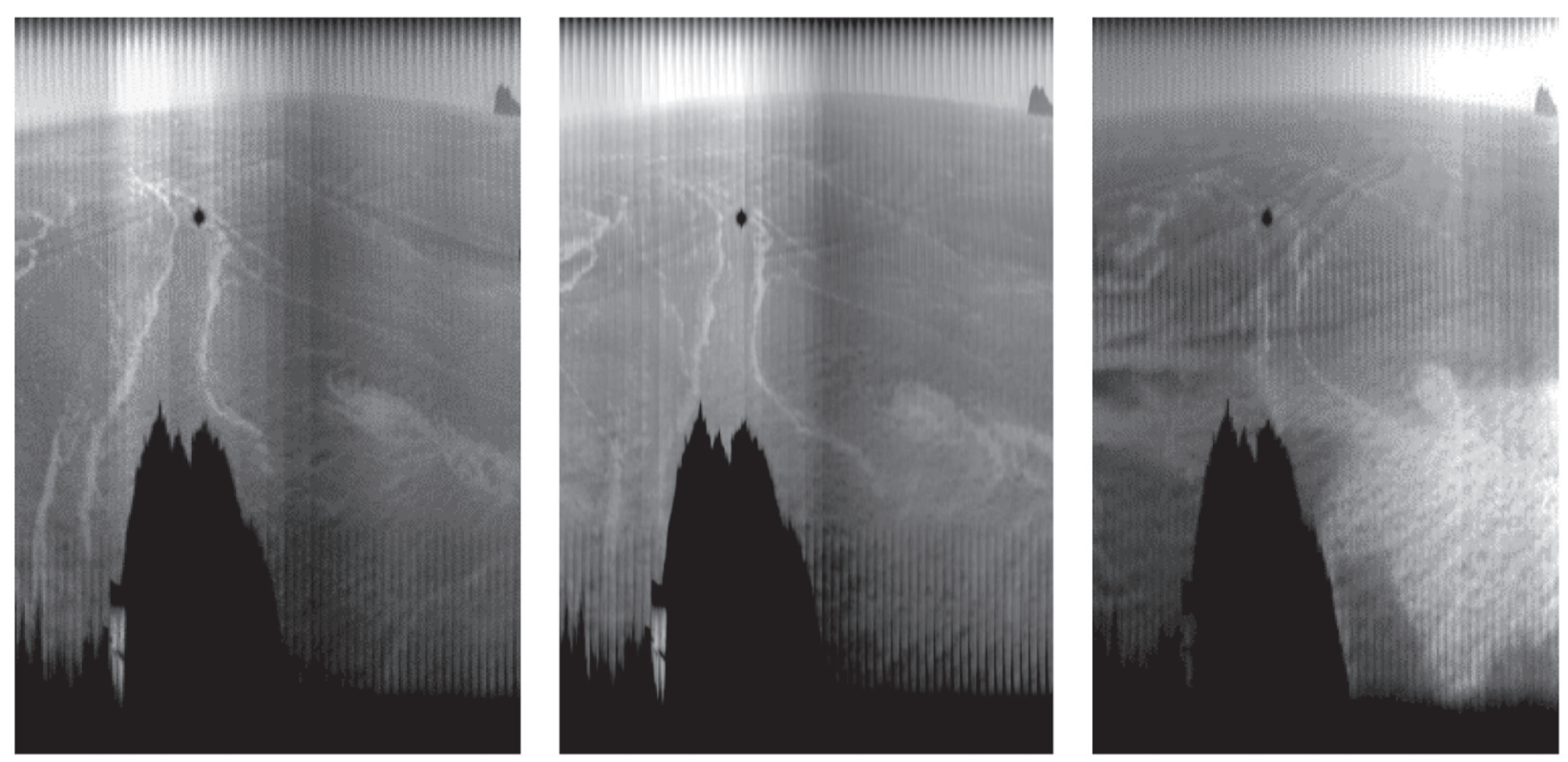

Figure 4. Three consecutive pictures of the coastal zone, taken at 19:14, 19:34 and 20:10 (from left to right). The images show the spread of two groups of dark stripes to the shore, accompanying two packets of internal waves. Also visible is the evolution of the coastal front (light bands on the surface).

\subsection{Measurement of internal waves in the water column}

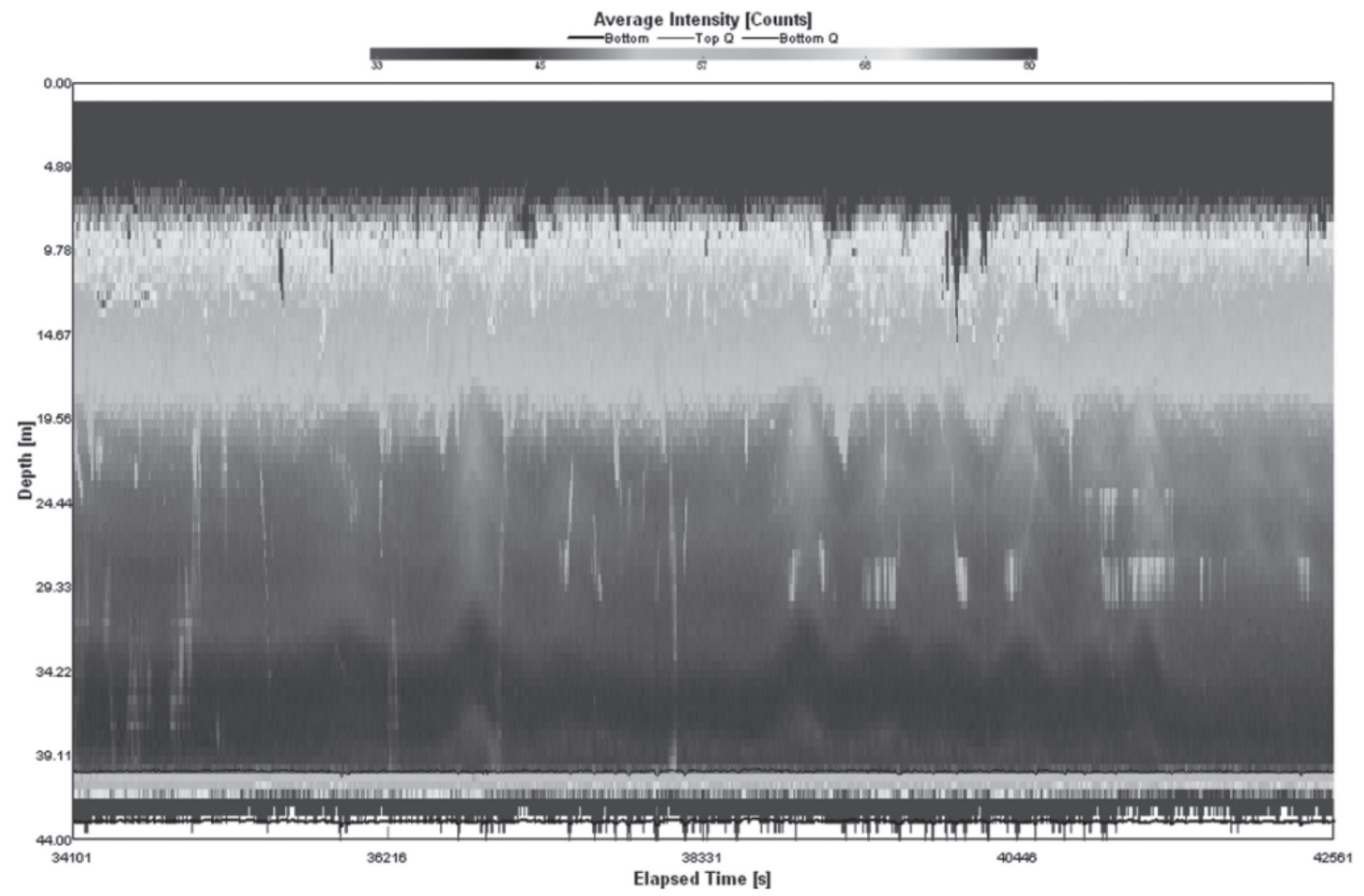

Figure 5a. 2.5 hour ADCP recording (backscattered signal intensity). Two trains are visible whose surface manifestations were recorded by the camera.

Measurements of internal waves and currents were carried out using the ADCP "Rio Grande $600 \mathrm{kHz}$ " looking down, mounted on an anchored yacht at a point in the sea with depths of about $40 \mathrm{~m}$, at a distance of $2.8 \mathrm{~km}$ from the coast. It is known that ADCP registers three flow components 
(two horizontal and one vertical). In addition, ADCP registers intensity of the backscattered signal, which allow one to evaluate the shape of wave profiles, as well as the amplitudes and periods of waves. In addition to the ADCP measurements, hourly soundings of the CTD probe from the surface to the bottom of the sea were carried out from the anchored yacht for $12 \mathrm{~h}$. As a result, additional information was obtained on the bottom location of the thermocline (within 10-15 $\mathrm{m}$ above the bottom) at the time of passage of the trains.

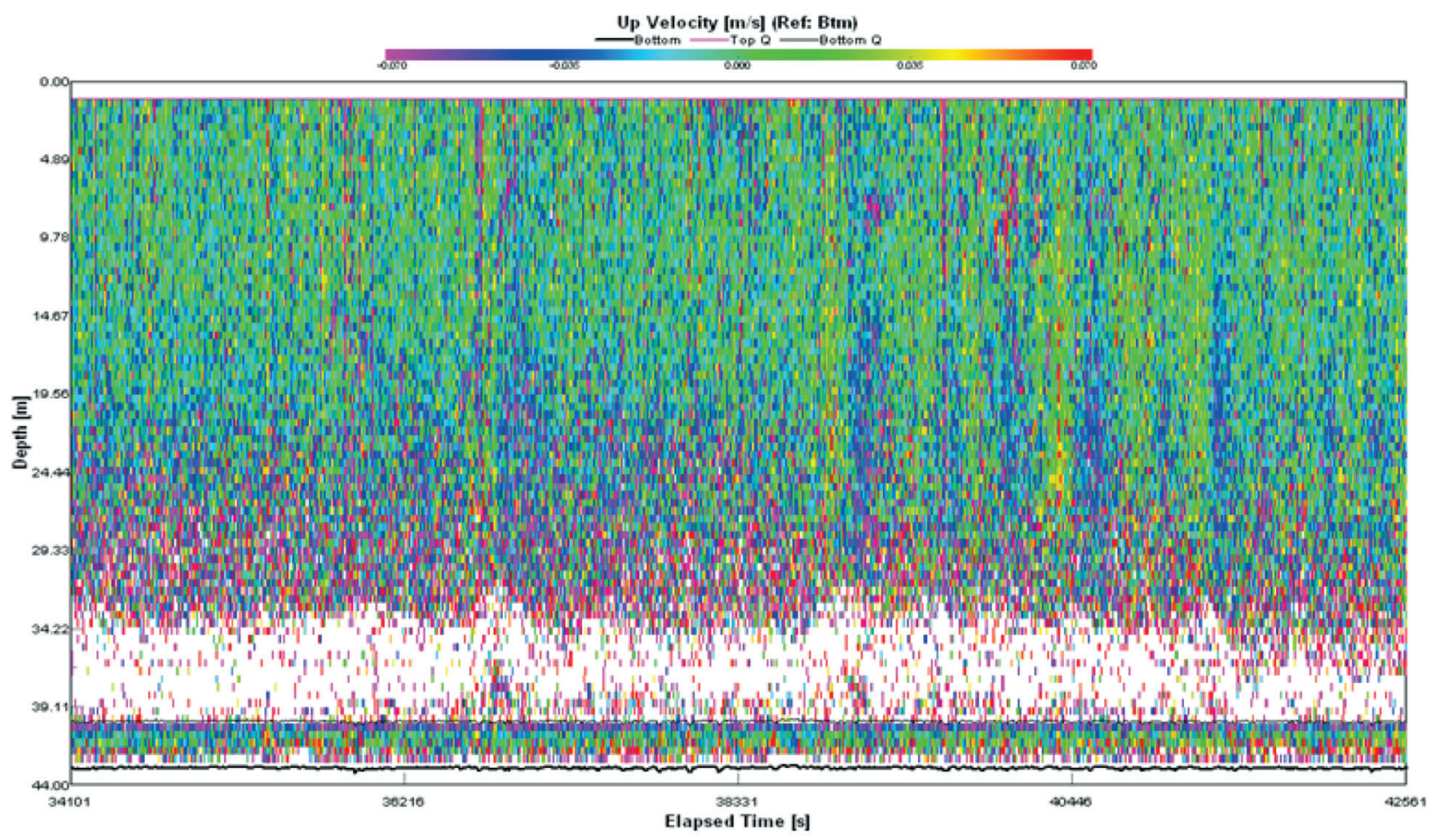

Figure 5b. 2.5 hour ADCP recording (up velocity). Two trains are visible whose surface manifestations were recorded by the camera. Up velocity in internal waves changes sign periodically with wave period.

Figure 5 shows a fragment of a recording of the intensity of backscattered signal and the vertical component of currents during the passage of trains of internal waves. Internal waves are visible due to layers of increased sound scattering in the water column, especially in the layer of pycnocline. ADCP recorded the following data. The first packet consisted of 3 waves, with a period of about 11.5 minutes, the second consisted of 6 waves with a period of 7.5 minutes. The wave heights in the trains had the following values: 6,7 , and $4 \mathrm{~m}$ in the first train; and 9, 6.5, 5, 6, 7, $9 \mathrm{~m}-$ in the second train. The measured vertical current velocities during the passage of packets of internal waves changed their sign throughout the water column and varied from -5 to $5 \mathrm{~cm} / \mathrm{s}$ with wave periodicity. The waves propagated along the bottom thermocline and had a soliton-like form of elevation waves, typical for nonlinear waves in these cases $[3,4]$.

\section{Conclusion}

The waves observed in this experiment are typical of the shelf of the Sea of Japan [5, 6]. They are usually generated in the region of the continental slope by the tidal current and then advance to the shore in the form of packets of internal solitons. In our case, they were accompanied by clearly distinguishable surface manifestations in the form of slick stripes with almost straight fronts several kilometers long. Before approaching the observation point, the internal waves passed the "turning point" (the point of change of internal wave polarity), transforming from the waves-depressions initially propagating along the shelf into the waves-elevations. This effect is widespread for intense internal waves when they move along the shelf to the coast [7].

Conducted combined monitoring made it possible to measure in detail the complete set of basic parameters of the observed internal waves. In addition to measuring the parameters of internal waves, 
the applied method of combined monitoring revealed the nonlinearity of the measured waves, as well as new features of the spatial structure of the field of internal waves in the coastal zone. In particular, the trains of internal waves, although spaced in time over a small interval, are approaching the coast at different angles. Which indicates possibly different mechanisms for their generation.

The use of measurements demonstrated in this paper can be a good complement to the technique of sub-satellite experiments [8] for studying the dynamics of the sea on the shelf.

\section{Acknowledgements}

The work was partially supported by the Russian Foundation for Basic Research (Project No. 19-05-00715).

\section{References}

[1] Serebryany A. N., Slick- and suloy generating processes in the sea, Internal waves, Sovremennye problemy distantsionnogo zondirovaniya Zemli iz kosmosa, 2012, Vol. 9(2), pp. 275-286.

[2] Konstantinov O.G., Pavlov A. N., Marine surface control video system, Instruments and Experimental Techniques, 2012, Vol. 6, pp. 121-123.

[3] Serebryany A. N., Nonlinearity Effects in Internal Waves onthe Shelf, Izvestiya Akademii Nauk SSSR, Fizika Atmosfery Okeana, 1990, Vol. 26(3), pp. 285-293.

[4] Serebryany A. N., Manifestation of the Properties of Solitons in the Internal Waves on the Shelf, Izvestiya Akademii Nauk SSSR, Fizika Atmosfery Okeana, 1993, Vol. 29(2), pp. 244-252.

[5] Serebryany A. N., Internal waves in the costal zone of the tidal sea, Oceanology, 1985, Vol. 25, 744-751.

[6] Serebryany A. N., Internal waves of a shelf and near the continental slope from data for a tower distributed temperature sensor, Oceanology, 1987, Vol. 27(2), 225-226.

[7] Serebryany A. N., Pao K. P., Passage of a nonlinear internal wave through a point of a coup on the shelf, Doklady Academy of Sciences, 2008, Vol. 420, pp. 543-547.

[8] Lavrova O. Yu., Mityagina M. I., Sabinin K. D., Serebryany A. N., Study of hydrodynamic processes in the shelf zone based on satellite data and subsatellite measurement, Sovremennye problemy distantsionnogo zondirovaniya Zemli iz kosmosa, 2015, Vol. 12(5), pp. 98-129. 